\title{
Patients with diabetes mellitus undergoing cardiac surgery are at greater risk for developing intraoperative myocardial acidosis
}

Dharam J. Kumbhani, MD, SM, Nancy A. Healey, BS, Hemant S. Thatte, PhD, Sammy Nawas, MD, Michael D. Crittenden, MD, Vladimir Birjiniuk, MD, Patrick R. Treanor, CCP, and Shukri F. Khuri, MD, FACS

From Surgical Services, VA Boston Healthcare System, Harvard Medical School and Brigham and Women's Hospital, Boston, Massachusetts.

This work was supported by the Richard Warren Surgical Research and Educational Fund, Westwood, Mass.

Shukri Khuri reports patents on the tissue $\mathrm{pH}$ monitoring system used in this study.

Presented at the American Heart Association Scientific Sessions 2004, New Orleans, La on Nov 8, 2004. Best Poster Finalist (Population Science).

Received for publication May 3, 2006; revisions received Nov 7, 2006; accepted for publication Nov 20, 2006.

Address for reprints: Shukri F. Khuri, MD, Chief, Cardiothoracic Surgery (112), VA Boston Healthcare System, 1400 V.F.W. Parkway, West Roxbury, MA 02132 (Email: shukri.khuri@med.va.gov).

J Thorac Cardiovasc Surg 2007;133:1566-72

$0022-5223 / \$ 32.00$

Copyright () 2007 by The American Association for Thoracic Surgery

doi:10.1016/j.jtcvs.2006.11.047
Objective: In patients undergoing cardiac surgery, intraoperative myocardial acidosis, which quantifies regional myocardial ischemia, has been shown to increase the risk of adverse postoperative outcomes. In this study, we sought to determine the course of intraoperative myocardial acidosis and its impact on postoperative survival in patients with diabetes mellitus undergoing cardiac surgery.

Methods: Intraoperative myocardial tissue $\mathrm{pH}_{37 \mathrm{C}}$ was continuously measured in the anterior and posterior left ventricular walls in 264 patients undergoing cardiac surgery; $74(28.0 \%)$ of the patients had diabetes (insulin-dependent diabetes: 54\%; non-insulin dependent diabetes: $46 \%$ ). The shortest time required to reach intraoperative myocardial tissue $\mathrm{pH}<6.34$ during aortic occlusion and $>6.73$ during reperfusion were compared in 3 patient groups: insulin-dependent, non-insulin dependent, and nondiabetic. These $\mathrm{pH}$ thresholds have been demonstrated to be associated with adverse postoperative long-term survival.

Results: The median times to reach intraoperative myocardial tissue $\mathrm{pH}_{37 \mathrm{C}}<6.34$ during aortic occlusion were 14,23 , and 36 minutes in the insulin-dependent, non-insulin dependent, and non-diabetic groups, respectively $(P=.003)$. The time taken to reach intraoperative myocardial tissue $\mathrm{pH}_{37 \mathrm{C}}>6.73$ during reperfusion was similar between the 3 groups. After adjusting for relevant pre- and intraoperative parameters, the risk of developing intraoperative myocardial tissue $\mathrm{pH}<6.34$ during aortic occlusion was $73 \%$ higher in patients with insulin-dependent diabetes mellitus $(P=.022)$ but the same in with patients with non-insulin dependent diabetes mellitus $(P=.98)$ when compared with patients without diabetes. Patients with insulin-dependent diabetes mellitus also had nearly threefold decrease in long-term survival compared with that of patients without diabetes $(P=.0007)$.

Conclusions: Patients with insulin-dependent diabetes mellitus undergoing cardiac surgery are at a greater risk of developing intraoperative myocardial acidosis/ ischemia and of decreased survival postoperatively compared with patients without diabetes.

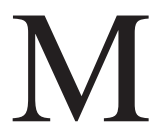
ore than 18 million Americans or about $6 \%$ of the total population of the United States have diabetes mellitus (DM). ${ }^{1}$ Its national prevalence among patients undergoing coronary artery bypass graft (CABG) surgery is as high as $28 \%{ }^{2}$ It is also a well-established risk factor for adverse outcomes following cardiac surgery. ${ }^{3-5}$ Any strategy that could improve outcomes in this group of patients would be a welcome addition to the surgical armamentarium.

Earlier studies from our institution demonstrated that myocardial tissue $\mathrm{pH}$ could be used as a reliable on-line measure of myocardial tissue ischemia during cardiac surgery, ${ }^{6,7}$ resulting in the development of a clinically usable probe. ${ }^{8}$ 


$$
\begin{aligned}
& \text { Abbreviations and Acronyms } \\
& \begin{aligned}
\mathrm{ATP} & =\text { adenosine triphosphate } \\
\mathrm{CABG} & =\text { coronary artery bypass graft } \\
\mathrm{CI} & =\text { confidence interval } \\
\mathrm{DM} & =\text { diabetes mellitus } \\
\mathrm{IDDM} & =\text { insulin-dependent diabetes mellitus } \\
\mathrm{NIDDM} & =\text { non-insulin dependent diabetes mellitus } \\
\mathrm{pH}_{37 \mathrm{C}} & =\text { myocardial tissue pH, corrected to } 37^{\circ} \mathrm{C} \\
\mathrm{RR} & =\text { relative risk } \\
\mathrm{VA} & =\text { Veterans Affairs }
\end{aligned}
\end{aligned}
$$

We recently demonstrated that intraoperative myocardial acidosis is associated with decreased long-term survival after cardiac surgery. In a cohort of 496 patients undergoing cardiac surgery who were followed for an average of 10.2 years, we determined that mean myocardial tissue $\mathrm{pH}$, corrected to $37^{\circ} \mathrm{C}\left(\mathrm{pH}_{37 \mathrm{C}}\right)<6.34$ during aortic occlusion and $\mathrm{pH}_{37 \mathrm{C}}<6.73$ at the end of reperfusion, were independent predictors of decreased long-term survival. ${ }^{9}$ In other studies, regional myocardial acidosis was shown to correlate with an increased risk of other adverse outcomes after cardiac surgery, including the need for intraoperative inotropic support, ${ }^{10} 30$-day mortality and morbidity, ${ }^{11}$ and unplanned hospital readmissions within 30 days and 6 months. $^{12}$

During the initial years of intraoperative metabolic monitoring, we passively monitored the myocardial tissue $\mathrm{pH}$ and observed how the myocardial $\mathrm{pH}$ varied as a result of different surgical and reperfusion practices. Subsequently, we developed specific methods and maneuvers aimed at reducing regional myocardial acidosis/ischemia intraoperatively. Collectively, these strategies formed the practice of "pH-guided myocardial management."13
The present study was undertaken during the period of myocardial $\mathrm{pH}$ monitoring in which intraoperative efforts to alter myocardial acidosis were not aggressively pursued. It aimed to quantify the risk and assess the impact of the development of intraoperative myocardial acidosis/ischemia during on-pump cardiac surgery in patients with diabetes mellitus.

\section{Materials and Methods \\ Patient Population}

Between 1987 and 1997, 264 patients underwent intraoperative on-line monitoring of myocardial tissue $\mathrm{pH}$ at the Veterans Affairs (VA) Medical Center, West Roxbury, Massachusetts; complete $\mathrm{pH}$ data for these patients, as well as data relating to DM status, including whether insulin dependent or not, were available. These patients were a subgroup of the cohort of 496 patients in whom differences in long-term mortality were studied. ${ }^{9}$ The study was approved by the Institutional Review Board at our institution, and all patients provided informed consent.

\section{$\mathrm{pH}_{37 \mathrm{C}}$ Measurement}

Myocardial tissue $\mathrm{pH}_{37 \mathrm{C}}$ was measured using the Khuri Tissue $\mathrm{pH}$ Monitoring System (Vascular Technology, Inc, Lowell, Mass) in adult patients undergoing cardiopulmonary bypass, as previously described. ${ }^{8,14}$ Two right-angled glass microelectrodes were inserted perpendicularly, 1 into the anterior and 1 into the posterior left ventricular wall, midway between the apex and the base. They were inserted immediately after beginning bypass, but before applying aortic occlusion, and were removed immediately after the patient was weaned from bypass. The $\mathrm{pH}$ monitoring system continuously measured myocardial tissue $\mathrm{pH}$ and temperature. For each time point for each patient, the lower of the anterior and posterior $\mathrm{pH}_{37 \mathrm{C}}$ values was used to define the magnitude of regional myocardial acidosis encountered in that patient (Figure 1).

Regional myocardial acidosis was also defined in terms of specific myocardial $\mathrm{pH}$ thresholds (6.34 during the period of aortic clamping and 6.73 during reperfusion). These thresholds have

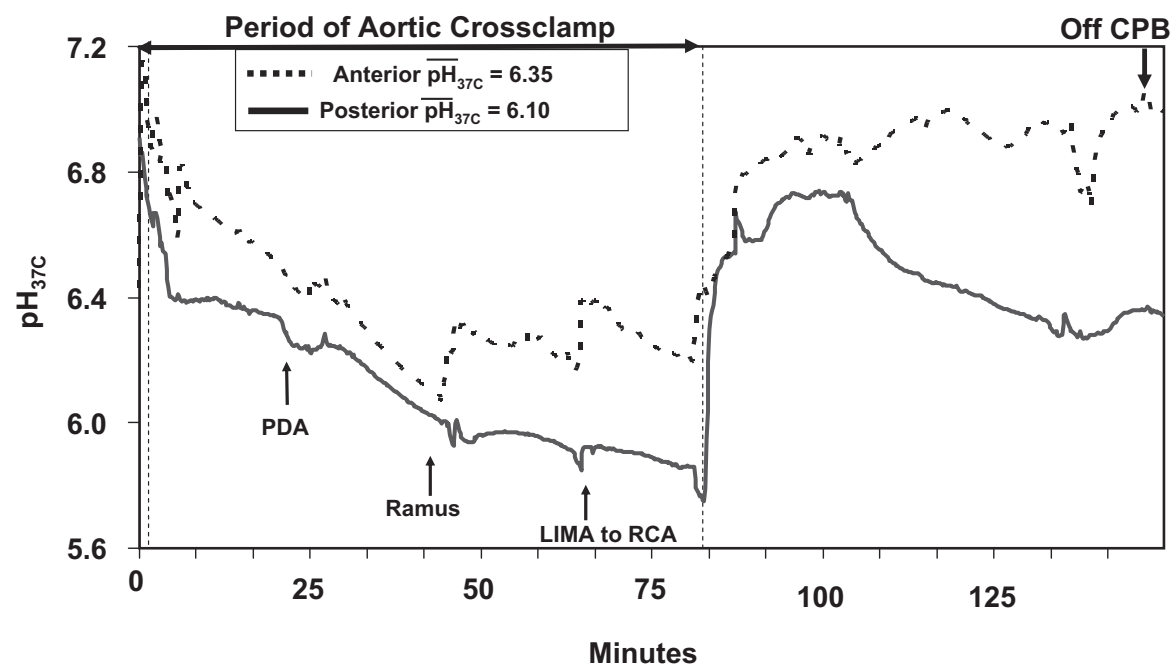

Figure 1. Intraoperative myocardial tissue $\mathrm{pH}_{37 \mathrm{c}}$ tracing of a 56-year old man with DM undergoing CABG surgery with 3 grafts. Cardioplegic solution was given in boluses through the aortic root at the beginning of aortic occlusion and through the proximal ends of the newly constructed grafts (indicated by arrows). The mean $\mathrm{pH}_{37 \mathrm{c}}$ during aortic occlusion indicated severe acidosis in both walls despite a total administration of $3500 \mathrm{~mL}$ of $4: 1$ blood cardioplegic solution. DM, diabetes mellitus; CABG, coronary artery bypass graft. 
been previously identified to be significant independent predictors of decreased long-term patient survival after cardiac surgery. ${ }^{9}$

\section{Perfusion and Myocardial Management Techniques}

Either mild hypothermia $\left(25^{\circ} \mathrm{C}\right)$ and topical cooling with ice slush using conventional bypass circuits (1987-1995) or systemic normothermia $\left(34^{\circ} \mathrm{C}-37^{\circ} \mathrm{C}\right)$ with heparin-bonded bypass circuits (1996-1997; Duraflo, Baxter Corp, Irvine, Calif) was used. Cold crystalloid cardioplegic solution or 4:1 blood cardioplegic solution was used for CABG procedures. When an operation included a concomitant valve replacement, 4:1 blood cardioplegic solution was used exclusively since 1991. In isolated CABG procedures, the distal anastomoses were performed first, through a single period of aortic clamping. The proximal anastomoses were performed by applying a side-biting clamp to the ascending aorta during reperfusion. In isolated CABG procedures, antegrade cardioplegic solution was delivered through the aortic root and through the proximal ends of constructed grafts; it was interrupted only during the construction of the distal anastomoses. In procedures where CABG surgery was combined with aortic valve replacement, the saphenous vein grafts were constructed first. Cardioplegic solution was initially given antegrade through the aortic root and subsequently through the orifice of the left main coronary artery and through the constructed grafts. During the valve replacement, cardioplegia was interrupted over 20-minute periods only when it interfered with the visualization of the operative field.

\section{Data Collection}

Specifically trained nurses and research assistants prospectively collected preoperative and intraoperative data on all patients, including diabetes status and whether insulin dependent or not.

\section{Data on Diabetes}

A patient was defined as being nondiabetic if the patient was normoglyemic or had hyperglycemia that was controlled by exercise and diet modifications alone. A patient was defined as having non-insulin dependent diabetes mellitus (NIDDM) if the patient required therapy with an oral hypoglycemic agent during the 2 weeks prior to surgery, and as having insulin-dependent diabetes mellitus (IDDM) if the patient required daily insulin therapy during the 2 weeks prior to surgery.

\section{Data on Long-term Survival}

The patients were tracked through the electronic patient records of the VA Boston Healthcare System and 9 additional referring VA medical centers in New England, research records of clinical studies in which many of the patients had been enrolled, and the VA Beneficiary Identification and Record Locator System, which has been shown to be $95 \%$ accurate in depicting the vital status of US veterans. ${ }^{9,15}$

\section{Data and Statistical Analysis}

Only patients with complete $\mathrm{pH}$ data, as well as data relating to DM status, were included in the analysis, which resulted in a data set of 264 patients. Missing values for other variables were not imputed. Age, body surface area, preoperative ejection fraction, preoperative serum creatinine, duration of aortic clamping and bypass, and total volume of cardioplegic solution used were treated as continuous variables. Only the operating surgeon $(n=3)$ was treated as a categorical variable, for which the surgeon with the lowest adverse outcomes rates was chosen as the reference category. All other variables, including year of study (1987-1990, 1991-1997) and type of surgery (CABG, valve \pm CABG), were treated as binary variables. Preoperative and intraoperative characteristics of the 3 study groups were compared using chi-square tests (or Fisher exact tests where necessary) for binary and categorical variables and analysis of variance for continuous variables. Kaplan-Meier curves compared the shortest times required by the 3 patient groups to develop regional myocardial acidosis during aortic occlusion $(<6.34)$ and for the reversal of this acidosis during reperfusion $(>6.73)$, as well as the long-term survival of the 3 patient groups. ${ }^{16}$ The Cox proportional hazards regression model was used to evaluate the relationship between risk factors and the development of acidosis, as well between diabetes and long-term survival. ${ }^{17}$ Initially, relative risks (RRs) and their confidence intervals (CIs) were estimated in a univariate model. Relevant preand intraoperative variables were then entered into a multivariate analysis. Two-way interactions of important risk factors were examined for statistical significance.

All statistical analyses were performed using SAS version 9.1 (SAS Institute, Cary, NC). All $P$ values were two-tailed. All CIs were calculated at the $95 \%$ level.

\section{Results}

Between January 1987 and September 1997, 264 patients underwent cardiac surgery with intraoperative on-line monitoring of myocardial tissue $\mathrm{pH}$; complete $\mathrm{pH}$ and diabetes information were available for these patients. Of these, 74 (28\%) had DM; among them were 40 (54\%) with NIDDM and $34(46 \%)$ with IDDM. The distribution of preoperative and intraoperative characteristics between the 3 study groups-IDDM, NIDDM, and nondiabetic-are shown in the Table 1. Patients with DM tended to have a larger body surface area, a higher preoperative serum creatinine, and a higher prevalence of peripheral vascular disease. After adjusting for multiple comparisons, patients with IDDM had significantly higher serum creatinine values compared with both patients without DM and patients with NIDDM $(P<$ .0017), and both patients with NIDDM and patients with IDDM had significantly higher incidence of femoral-popliteal disease as compared with patients without DM $(P<$ .017). At our institution, patients with DM were more likely to undergo CABG surgery than valve surgery. Patients with DM, particularly those with IDDM, also tended to have a significantly lower $\mathrm{pH}_{37 \mathrm{C}}$ prior to aortic occlusion. There was also a statistical trend observed toward low mean $\mathrm{pH}_{37 \mathrm{C}}$ during aortic occlusion in patients with DM compared with patients without DM. After adjusting for multiple comparisons, patients with IDDM had a significantly lower $\mathrm{pH}_{37 \mathrm{C}}$ compared with patients without DM (6.45 vs $6.57 ; P<$ .017)

Kaplan-Meier curves comparing the shortest time taken by the 3 patient groups to develop regional myocardial 
TABLE 1. Baseline characteristics of study population

\begin{tabular}{|c|c|c|c|c|}
\hline Variable & Nondiabetics $(\mathrm{n}=190)$ & NIDDM $(n=40)$ & IDDM $(n=34)$ & $P^{*}$ \\
\hline \multicolumn{5}{|l|}{ Preoperative or demographic variables } \\
\hline Age (y) & $64.9 \pm 9.7$ & $65.8 \pm 8.4$ & $63.8 \pm 9.9$ & .67 \\
\hline Female & $4(2.1 \%)$ & $1(2.5 \%)$ & $1(2.9 \%)$ & .76 \\
\hline Prior myocardial infarction & $70(41.4 \%)$ & $22(57.9 \%)$ & $20(58.8 \%)$ & .055 \\
\hline NYHA class III/IV & $107(58.8 \%)$ & $18(45.0 \%)$ & $19(55.9 \%)$ & .28 \\
\hline ASA class IV/V & $51(27.4 \%)$ & $12(30.0 \%)$ & $12(35.3 \%)$ & .64 \\
\hline Current smoker & $57(30.3 \%)$ & $12(30.0 \%)$ & $9(26.5 \%)$ & .90 \\
\hline Emergency surgery & $7(3.8 \%)$ & $2(5.0 \%)$ & $2(5.9 \%)$ & .54 \\
\hline Body surface area $\left(\mathrm{kg} / \mathrm{m}^{2}\right)$ & $1.9 \pm 0.2$ & $2.0 \pm 0.2$ & $2.0 \pm 0.2$ & .045 \\
\hline Preoperative ejection fraction (\%) & $50.2 \pm 16.5$ & $53.7 \pm 16.0$ & $46.5 \pm 18.3$ & .32 \\
\hline Chronic obstructive pulmonary disease & $57(30.3 \%)$ & $14(35.0 \%)$ & $12(35.3 \%)$ & .75 \\
\hline Serum creatinine before surgery (mg\%) & $1.2 \pm 0.3$ & $1.1 \pm 0.3$ & $1.4 \pm 0.9$ & .0031 \\
\hline Presence of femoral-popliteal disease & $32(17.2 \%)$ & $14(35.0 \%)$ & $17(50.0 \%)$ & $<.0001$ \\
\hline \multicolumn{5}{|l|}{ Surgeon } \\
\hline No. 1 & $121(63.7 \%)$ & $25(62.5 \%)$ & $20(58.8 \%)$ & .87 \\
\hline No. 2 & $63(33.2 \%)$ & $15(37.5 \%)$ & $12(35.3 \%)$ & .86 \\
\hline No. 3 & $5(2.6 \%)$ & 0 & $2(5.9 \%)$ & .74 \\
\hline \multicolumn{5}{|l|}{ Type of operation } \\
\hline CABG & $94(49.5 \%)$ & $23(57.5 \%)$ & $26(76.5 \%)$ & (ref) \\
\hline Valve \pm CABG & $96(50.5 \%)$ & $17(42.5 \%)$ & $8(23.5 \%)$ & .013 \\
\hline \multicolumn{5}{|l|}{ Intraoperative variables } \\
\hline Duration of bypass (min) & $165.3 \pm 63.7$ & $157.5 \pm 46.4$ & $143.6 \pm 49.3$ & .16 \\
\hline Duration of aortic occlusion (min) & $89.8 \pm 41.6$ & $84.8 \pm 34.7$ & $75.5 \pm 38.5$ & .16 \\
\hline $\begin{array}{l}\text { Total amount of cardioplegic solution, per } \\
\text { hour of aortic occlusion }(\mathrm{mL})\end{array}$ & $3292.7 \pm 2640.0$ & $3089.5 \pm 2160.4$ & $2632.8 \pm 1915.9$ & .40 \\
\hline Crystalloid cardioplegic solution & $21(11.1 \%)$ & $3(7.5 \%)$ & $2(5.9 \%)$ & .29 \\
\hline Internal thoracic artery use & $50(26.6 \%)$ & $12(30.0 \%)$ & $12(35.3 \%)$ & .56 \\
\hline $\mathrm{pH}_{37 \mathrm{C}}$ prior to aortic occlusion & $6.64 \pm 0.28$ & $6.63 \pm 0.33$ & $6.49 \pm 0.26$ & .033 \\
\hline Mean $\mathrm{pH}_{37 \mathrm{C}}$ during aortic occlusion & $6.57 \pm 0.31$ & $6.54 \pm 0.31$ & $6.45 \pm 0.31$ & .12 \\
\hline Mean $\mathrm{pH}_{37 \mathrm{C}}<6.34$ during aortic occlusion & $33(17.55 \%)$ & $9(22.5 \%)$ & $11(32.4 \%)$ & .13 \\
\hline $\mathrm{pH}_{37 \mathrm{C}}$ at end of reperfusion & $6.98 \pm 0.33$ & $7.01 \pm 0.31$ & $6.91 \pm 0.34$ & .34 \\
\hline
\end{tabular}

${ }^{*}$ Chi-square/Fisher exact test for binary/categorical variables and analysis of variance for continuous variables. NIDDM, Non-insulin dependent diabetes mellitus; IDDM, insulin-dependent diabetes mellitus; NYHA, New York Heart Association; ASA, American Society of Anesthesiologists; CABG, coronary artery bypass graft surgery; (ref), reference category; $\mathrm{pH}_{37 \mathrm{C}^{\prime}}=$ myocardial tissue $\mathrm{pH}$ adjusted to $37^{\circ} \mathrm{C}$. Values in the table represent mean \pm standard deviation, unless mentioned otherwise.

acidosis $\left(\mathrm{pH}_{37 \mathrm{C}}<6.34\right)$ during aortic occlusion are shown in Figure 2. Patients with DM developed intraoperative acidosis earlier than did patients without DM after aortic occlusion. The median times were 14 minutes, 23 minutes, and 36 minutes for patients with IDDM, patients with NIDDM, patients without DM (log-rank test $P=.003$ ). There was no difference in the shortest time taken to reverse regional myocardial acidosis during reperfusion between the 3 groups: the median times were 11 minutes, 6 minutes, and 7 minutes for patients with IDDM, patients with NIDDM, and patients without $\mathrm{DM}$, respectively (log-rank test $P=.70$ ).

Univariate Cox regression analysis, with time to development of regional acidosis during aortic occlusion as the dependent variable, revealed that patients with NIDDM had a $31 \%$ greater risk of developing intraoperative myocardial acidosis when compared with patients without DM (RR = $1.31,95 \% \mathrm{CI}=0.87-1.96 ; P=.2)$. In contrast, patients with IDDM had a significantly elevated $95 \%$ greater risk $(\mathrm{RR}=1.95,95 \% \mathrm{CI}=1.29-2.96 ; P=.002)$ when compared with patients without DM. The final multivariate model, which was adjusted for relevant covariates, including age, gender, New York Heart Association class, American Society of Anesthesiologists class, smoking status, body surface area, serum creatinine before surgery, presence of peripheral vascular disease, type of surgery, year of surgery, surgeon, and type of cardioplegic solution used, revealed that patients with IDDM continued to have a significantly higher risk of developing intraoperative myocardial ischemia when compared with patients without DM $(\mathrm{RR}=1.73,95 \% \mathrm{CI}=1.08-2.75 ; P=.022)$. The risk for patients with NIDDM was nonsignificant $(\mathrm{RR}=1.01,95 \%$ $\mathrm{CI}=0.60-1.68 ; P=.98$ ).

Data on long-term survival were available for all patients in our cohort, with a mean follow-up of 10.2 years, as 


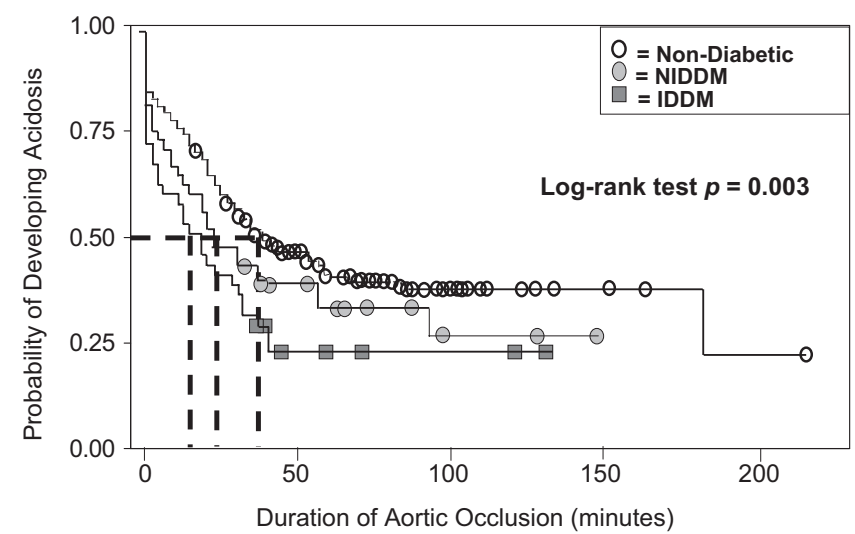

Figure 2. Kaplan-Meier curves comparing the median times taken to develop regional myocardial acidosis during aortic occlusion ( $\mathrm{pH}<6.34$ ) in the 3 patient groups: IDDM (insulindependent diabetes mellitus), NIDDM (non-insulin dependent diabetes mellitus), and nondiabetic. The median times were 14,23 , and 36 minutes, respectively ( $\log$-rank test $P=.003$ ).

mentioned earlier. Accordingly, we compared the long-term survival of the 3 groups of patients and found that the median survival in patients with IDDM was 4.59 years, as compared with a median survival of 11.07 years in patients without DM. Although the 50th percentile for mortality in patients with NIDDM was not defined, the survival curves for patients with NIDDM and patients without DM appeared to be similar. The log-rank test comparing the survival curves had a $P$ value of .0014 (Figure 3 ). The adjusted hazard ratio of long-term mortality was $0.97(95 \% \mathrm{CI}=$ $0.50-1.85 ; P=.92)$ in patients with NIDDM and $2.62(95 \%$ $\mathrm{CI}=1.50-4.57 ; P=.0007)$ in patients with IDDM when compared with patients without DM, indicating that only patients with IDDM had an adverse postoperative survival compared with patients without DM.

We also compared immediate postoperative outcomes among the 3 groups. There was no difference between patients without DM, patients with NIDDM, and patients with IDDM in the incidence of 30 -day mortality ( $4.7 \%$ vs $2.5 \%$ vs $0 ; P=.19$ ) or perioperative myocardial ischemia $(5.9 \%$ vs $7.5 \%$ vs $8.8 \% ; P=.80)$.

\section{Discussion}

Based on our observation that the median time to development of intraoperative myocardial acidosis after crossclamp was significantly lower in patients with IDDM than in patients without DM, the principal finding of our study is that patients with IDDM are more vulnerable to the development of intraoperative myocardial acidosis during cardiac surgery than patients without DM. They had a statistically significant $73 \%$ higher risk of developing regional myocardial acidosis compared with patients without DM, after adjusting for relevant

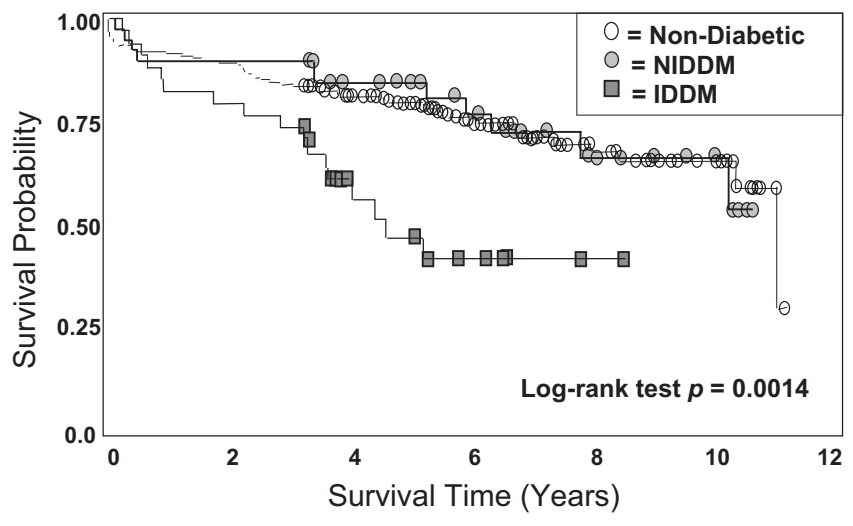

Figure 3. Kaplan-Meier curves comparing long-term survival in the 3 patient groups: IDDM (insulin-dependent diabetes mellitus), NIDDM (non-insulin dependent diabetes mellitus), and nondiabetic. Patients with IDDM had a median survival of 4.59 years, and patients without DM had a median survival of 11.07 years. The 50th percentile for mortality in patients with NIDDM was not defined (log-rank test $\boldsymbol{P}=.0014)$.

clinical variables. They also showed a nearly threefold increase in their long-term mortality compared with patients without DM. There was no significant difference in the risk of developing intraoperative myocardial acidosis or long-term survival in patients with NIDDM when compared with patients without DM. A greater emphasis on myocardial protection in patients with IDDM is thus necessary. To the best of our knowledge, this is the first clinical study demonstrating an increased susceptibility to developing intraoperative myocardial acidosis in patients with IDDM.

Our findings that patients with DM have a higher prevalence of obesity, peripheral vascular disease, and renal insufficiency are consistent with current knowledge about diabetes. ${ }^{3,4,18}$ They may also have more advanced, diffuse coronary disease, making myocardial management during CABG surgery more difficult and less successful. ${ }^{18}$ Numerous methods to improve myocardial protection in patients with DM have been proposed; including a recent study by Furnary et al, ${ }^{4}$ who found that a continuous insulin infusion during the perioperative period to aggressively control hyperglycemia in patients with DM undergoing CABG surgery (Portland protocol) conferred a survival benefit.

The relationship between regional myocardial acidosis and regional myocardial ischemia has been well established. Myocardial tissue $\mathrm{pH}$, measured with the technology employed in this study, has been shown to be reflective of regional myocardial tissue $\mathrm{pCO}_{2}$ measured with mass spectrometry. ${ }^{7}$ Under ischemic conditions, the respective measurements of regional myocardial tissue $\mathrm{pH}$ and $\mathrm{pCO}_{2}$ have been shown to correlate with each other ${ }^{7}$ and with adjacent intramural ST-segment changes on the electrocardiogram, ${ }^{19}$ 
regional myocardial blood flow, ${ }^{20}$ qualitative ultrastructural ischemic changes, ${ }^{6,20}$ and intracellular $\mathrm{pH}$ and intracellular high-energy phosphates. ${ }^{21}$ Therefore, myocardial acidosis in the patient population studied can be considered a surrogate for regional myocardial ischemia.

Mechanistically, there could be several reasons that explain why patients with DM should be more susceptible to the development of myocardial acidosis and ischemia during the period of aortic clamping. To begin with, patients with DM develop hyperglycemia and dyslipidemia-induced endothelial dysfunction, with resultant advanced macroangiopathy and microangiopathy in the vascular system, including in the coronary circulation. ${ }^{22}$ Moreover, studies have also demonstrated that despite angiographically normal epicardial coronary arteries, the coronary vasodilator reserve is frequently impaired in patients with $\mathrm{DM}^{23}$; because of this, the washout of $\mathrm{H}^{+}$may be impaired as a result of poor perfusion, leading to localized acidosis in the myocardium. Similarly, these factors may reduce the capacity of the diabetic myocardium to sustain prolonged periods of ischemia and, in fact, probably engender some amount of ischemia in the resting myocardium as well. This correlates very well with our observation of a statistically significant lower myocardial $\mathrm{pH}_{37 \mathrm{C}}$ in patients with $\mathrm{DM}$ compared with patients without DM even prior to aortic occlusion. Once subjected to global ischemia following aortic clamping, their myocardial reserve is depleted quickly, manifested by an early drop in $\mathrm{pH}_{37 \mathrm{C}}$ on crossclamp.

At the cellular level, several pathways may be operative, which could explain an increased susceptibility of patients with IDDM to intraoperative myocardial acidosis. Normal myocardium utilizes several substrates, including free fatty acids, glucose, pyruvate, lactate, and ketones for the production of adenosine triphosphate (ATP) ${ }^{24}$ However, insulin deficiency impairs both aerobic and anaerobic metabolic pathways of ATP generation, resulting in increased $\mathrm{O}_{2}$ consumption, buildup of $\mathrm{CO}_{2}$, acetyl coenzyme A, pyruvate, and lactic acid, ${ }^{25,26}$ which in turn results in localized respiratory and metabolic acidosis in the tissues. Additionally, ongoing rapid hydrolysis of ATP and lactic acid buildup lead to a decrease in intracellular $\mathrm{pH}_{\mathrm{i}}$ and impaired ATP-dependent cellular functions. ${ }^{27,28}$ Increase in intracellular $\mathrm{H}^{+}$concentration results in the accumulation of $\mathrm{Na}^{+}$in the cell due to the activation of $\mathrm{Na}^{+} / \mathrm{H}^{+}$antiporter attempting to restore internal $\mathrm{pH}$, which in turn results in accumulation of $\mathrm{H}^{+}$in the extracellular milieu, contributing further to the regional acidosis.

The combination of increased acidosis in patients with DM and the adverse impact of intraoperative myocardial acidosis on long-term survival, which we have recently reported, ${ }^{9}$ suggests that patients with IDDM should have decreased survival after cardiac surgery compared with that of patients without DM. Our study confirms this assumption by demonstrating that long-term mortality in patients with IDDM is significantly increased by 2.6 times when compared with that of patients without DM. Our findings are in concordance with the findings of other investigators, who have demonstrated a greater long-term mortality in patients with DM, both after percutaneous and surgical revascularization, when compared with patients without DM. ${ }^{3,5,29}$

Our data are derived from a time period of myocardial $\mathrm{pH}$ monitoring when intraoperative efforts to alter myocardial acidosis were not pursued unless $\mathrm{pH}$ reached acidotic levels following the application of aortic crossclamp. Hence, the mean $\mathrm{pH}_{37 \mathrm{C}}$ during the total period of aortic crossclamping, which may have been altered by $\mathrm{pH}$-guided myocardial management, would not be as discriminant as the initial course of myocardial $\mathrm{pH}$ changes in depicting susceptibility to acidosis during this period. In the light of the current and other outcomes studies, ${ }^{9-12}$ the development of intraoperative myocardial acidosis during cardiac surgery is aggressively avoided at our institution through the implementation of $\mathrm{pH}$-guided myocardial management, which is directed at reducing or totally ameliorating intraoperative regional myocardial acidosis.

The main limitations of the current study are the small sample size of the study population, the fact that it emanated from a single institution, and that any validation of these findings would require prospective multicenter studies. A multicenter study and other studies all aimed at validating the observations made in the course of pH-guided myocardial management are currently underway. The small sample size perhaps also hindered our ability to detect subtle differences in susceptibilities between patients with NIDDM and patients without DM. Another limitation of our study is the lack of data on the level of glycemic control in our patients, both intraoperatively and perioperatively, as reflected by hemoglobin A1c levels. That would have enabled us to study the relationship between pre- and perioperative glucose levels and the development of myocardial acidosis during aortic occlusion and a potential causal relationship between higher glucose levels and early development of myocardial acidosis.

In summary, patients with IDDM are more likely to develop severe intraoperative regional myocardial ischemic acidosis during cardiac surgery. They also have significantly decreased long-term survival compared with patients without DM. A greater emphasis on adequate myocardial protection during cardiac surgery in these high-risk patients is warranted.

We thank Mr Sidney Atwood, Harvard School of Public Health, for his help with the statistical analysis. 


\section{References}

1. National Diabetes Education Program. Guiding principles for diabetes care: for health care providers. NIH Publication No. 99-4343. April 2004.

2. Edwards FH, Grover FL, Shroyer AL, Schwartz M, Bero J. The Society of Thoracic Surgeons National Cardiac Surgery Database: current risk assessment. Ann Thorac Surg. 1997;63:903-8.

3. Thourani VH, Weintraub WS, Stein B, Gebhart SS, Craver JM, Jones EL, et al. Influence of diabetes mellitus on early and late outcome after coronary artery bypass grafting. Ann Thorac Surg. 1999;67:1045-52.

4. Furnary AP, Gao G, Grunkemeier GL, Wu Y, Zerr KJ, Bookin SO, et al. Continuous insulin infusion reduces mortality in patients with diabetes undergoing coronary artery bypass grafting. J Thorac Cardiovasc Surg. 2003;125:1007-21.

5. Koch CG, Weng YS, Zhou SX, Savino JS, Mathew JP, Hsu PH, et al. Ischemia Research and Education Foundation; Multicenter Study of Perioperative Ischemia Research Group. Prevalence of risk factors, and not gender per se, determines short- and long-term survival after coronary artery bypass surgery. J Cardiothorac Vasc Anesth. 2003;17: 585-93.

6. Lange R, Kloner RA, Zeiler M, Carlson N, Seiler M, Khuri SF. Time course of ischemic alteration during normothermic and hypothermic arrest and its reflection by online monitoring of tissue $\mathrm{pH}$. J Thorac Cardiovasc Surg. 1983;86:418-34.

7. Khuri SF, Kloner RA, Karaffa SA, Marston W, Taylor AD, Lai NC, et al. The significance of the late fall in myocardial PCO2 and its relationship to myocardial $\mathrm{pH}$ after regional occlusion in the dog. Circ Res. 1985;56:537-47.

8. Khuri SF, Josa M, Marston W, Braunwald NS, Smith B, Tow D, et al. First report of intramyocardial $\mathrm{pH}$ in man: II. Assessment of adequacy of myocardial preservation. J Thorac Cardiovasc Surg. 1983;86:66778.

9. Khuri SF, Healey N, Hossain M, Birjiniuk V, Crittenden MD, Josa M, et al. Intraoperative regional myocardial acidosis and reduction in long term survival after cardiac surgery. J Thorac Cardiovasc Surg. 2005; 129:372-81.

10. Kumbhani DJ, Healey NA, Birjiniuk V, Crittenden MD, Treanor PR, Al-Tabbaa AK, et al. Intraoperative regional myocardial acidosis predicts the need for inotropic support in cardiac surgery. Am J Surg. 2004;188:474-80.

11. Kumbhani DJ, Healey NA, Biswas KS, Birjiniuk V, Crittenden MD, Treanor PR, et al. Adverse 30-day outcomes after cardiac surgery: predictive role of intraoperative myocardial acidosis. Ann Thorac Surg. 2005;80:1751-7.

12. Kumbhani DJ, Healey NA, Thatte HS, Crittenden MD, Birjiniuk V, Treanor PR, et al. Readmission after cardiac surgery: the role of intraoperative myocardial acidosis. J Am Coll Surg. 2004;199:S71 (Abstract).
13. Khuri SF. Myocardial pH monitoring system. Available at http:// www.terumo-cvs.com/for_clinicians/khuriph. Accessed May 2, 2006.

14. Khabbaz KR, Zankoul F, Warner KG. Intraoperative metabolic monitoring of the heart: I.I. Online measurement of myocardial tissue $\mathrm{pH}$. Ann Thorac Surg. 2001;72:S2227-34.

15. Page WF, Mahan CM, Kang HK. Vital status ascertainment through the files of the Department of Veteran Affairs and the Social Security Administration. Ann Epidemiol. 1996;6:102-9.

16. Kaplan EL, Meier P. Nonparametric estimation from incomplete observations. J Am Stat Assoc. 1958;53:457-81.

17. Cox DR. Regression models and life tables. J R Stat Soc B. 1972;34: 187-220.

18. Jessen ME. Glucose control during cardiac surgery: How sweet it is. J Thorac Cardiovasc Surg. 2003;125:985-7.

19. Khuri SF, Flaherty JT, O’Riordan JB, Pitt B, Brawley RK, Donahoo JS, et al. Changes in intramyocardial ST segment voltage and gas tensions with regional myocardial ischemia in the dog. Circ Res. 1975;37:455-63.

20. Khuri SF, Kloner RA, Hillis LD, Tow DE, Barsamian EM, Maroko $\mathrm{PR}$, et al. Intramural $\mathrm{pCO}_{2}$ : a reliable index of the severity of myocardial ischemic injury. Am J Physiol. 1979;237:H253-9.

21. Axford TC, Dearani JA, Khait I, Park WM, Patel MA, Doursounian M, et al. Electrode-derived myocardial $\mathrm{pH}$ measurements reflect intracellular myocardial metabolism assessed by 31P NMR spectroscopy during ischemia. J Thorac Cardiovasc Surg. 1992;103:902-7.

22. Skrha J. Pathogenesis of angiopathy in diabetes. Acta Diabetol. 2003; 40(suppl 2):S324-9.

23. Nahser PJ Jr, Brown RE, Oskarsson H, Winniford MD, Rossen JD. Maximal coronary flow reserve and metabolic coronary vasodilation in patients with diabetes mellitus. Circulation. 1995;91:635-40.

24. Taegtmeyer H. Carbohydrate interconversions and energy production. Circulation. 1985;72(5 Pt 2):IV1-8.

25. Kantor PF, Dyck JR, Lopaschuk GD. Fatty acid oxidation in the reperfused ischemic heart. Am J Med Sci. 1999;318:3-14

26. Szabo Z, Hakanson E, Jorfeldt L, Svedjeholm R. Myocardial uptake and release of substrates in type II diabetics undergoing coronary surgery. Scand Cardiovasc J. 2001;35:207-11.

27. Halestrap AP, Wang X, Poole RC, Jackson VN, Price NT. Lactate transport in heart in relation to myocardial ischemia. Am J Cardiol. 1997;80:17A-25A.

28. Halestrap AP. The mitochondrial permeability transition: its molecular mechanism and role in reperfusion injury. Biochem Soc Symp. 1999; 66:181-203.

29. Barsness GW, Peterson ED, Ohman EM, Nelson CL, DeLong ER, Reeves JG, et al. Relationship between diabetes mellitus and long-term survival after coronary bypass and angioplasty. Circulation. 1997;96: 2551-6. 